\title{
THE PHYSIOLOGICAL AND BIOCHEMICAL MECHANISMS OF CINNAMOMUM CAMPHORA XYLEM EXTRACTS INHIBIT WOOD-DECAY FUNGI
}

\author{
Huimin Zhang, Kai Tu, Qiandong Hou \\ Guizhou University \\ P. R. ChinA \\ Hui Lin \\ Ningde Normal University \\ P. R. CHINA \\ QUAN Li \\ Kaili University \\ P. R. CHINA \\ (Received October 20i9)
}

\begin{abstract}
The present study investigated the physiological and biochemical mechanism of extracts derived from Cinnamomum camphora (L.) Presl. The methanol and chloroform extracts of C. camphora xylem exhibited inhibitory activity against oxygen consumption in Coriolus versicolor and Gloeophyllum trabeum. The inhibitory effect of cellulose secreted by G. trabeum was concentration-dependent. The application of the ethyl acetate extracts of $C$. camphora xylem on the G. trabeum hyphae resulted in an improvement in electric conductivity, which followed a concentration-dependent fashion. Protein permeability increased with higher concentrations of the ethyl acetate extracts of $C$. camphora xylem. This research provided theoretical basis for understanding of the physiological and biochemical mechanisms of C. camphora extracts inhibit wood-decay fungi and the development of natural extracts as wood preservatives.
\end{abstract}

KEYWORDS: Coriolus versicolor, Gloeophyllum trabeum, Cinnamomum camphora, oxygen consumption, electric conductivity, protein permeability.

\section{INTRODUCTION}

Wood decay caused by fungal infection severely reduces the quality of timber including its main physical and mechanical properties, as well as influences the turnout rate and service 
life of wood products, thereby resulting in huge economic losses every year (Kahl et al. 2017). Traditional wood preservatives such alkaline copper quaternary (ACQ) and chromium copper arsenic (CCA) contain toxic compounds that may cause environment pollution (Janin et al. 2011, Mehmet et al. 2009, Palanti et al. 2009), therefore, new types of wood preservatives are currently in high demand. Recent studies have focused on anti-bacterial and anti-corrosion performance of plant extracts because these are generally environment friendly (Syehee et al. 2010), efficient broad-spectrum (Suhua et al. 1973), and targeted antimicrobial therapy (Schubert et al. 2008, Susi et al. 2011). Cinnamomum camphora (L.) Presl. (C. camphora) is one of the most important hardwood species indigenous to China (Roszaini et al. 2013). C. camphora is a strong decay resistance wood species. It has decay resistance performance due to its extracts has a significant anti-fungal activity and has been applied in the antiseptic field. More and more studies have shown that the extractives of $C$. camphora has anti-bacterial, anti-inflammatory, desinsectization and other effects ( $\mathrm{Li}$ et al. 2014, Liu et al. 2018). It has good prospect in development and application for the extracts from the xylem of C. camphora.

The research and development of $C$. camphora extractives usually focuse on evaluating the decay resistance performance of C. camphora extractives by wood preservation test, as well as their anti-microbial and insecticidal performance (Guo et al. 2016, Lee et al. 2006, Li et al. 2018). Reporting the volatile ingredients isolated from a fresh tree of C. camphora (camphor tree) and $98.68 \%$ of the constituents consisting 24 components from the tree (Miyazawa et al. 2001). However, the mechanism of the C. camphora xylem extractives inhibits Gloeophyllum trabeum (G. trabeum) and Coriolus versicolor (C. versicolor) is unknown up to now (Kerem et al. 1999, Zhang et al. 2016). In order to reveal the relation between secondary metabolite of $C$. camphora and wood-decaying fungus. Author think that it is necessary to comprehensively investigate the physiological and biochemical mechanisms of $C$. camphora extractives in wood preservatives from the reality needs of wood preservation and protection (Bhardwaj et al. 2012, Kumari et al. 2015).

In this study, the effect of C. camphora xylem extracts on G. trabeum and C. versicolor oxygen consumption, cellulase activity (Leskinen et al. 2015, Matsubara and Kuroda 2008), electrical conductivity, and leakage protein content was investigated to explore the physiological and biochemical mechanisms of C. camphora extracts against wood-decay fungus and their possible targets ( $\mathrm{Li}$ et al. 2016, Voda et al. 2003). This paper provided theoretical basis for understanding of the anti-fungal mechanism of $C$. camphora xylem extractives against wood-decaying fungus and the development of natural extracts as wood preservatives (Schultz et al. 2007).

\section{MATERIAL AND METHODS}

\section{Materials}

The xylem of C. camphora was pulverized and $100 \mathrm{~g}$ of the pulverized powder was placed at the bottom of a round-bottom flask and used in heat reflux extraction. Hot water, methanol, acetone, ethyl acetate, and chloroform were used as solvents, respectively. The extraction temperature of each solvent was their respective boiling point temperature. The raw materials were extracted for twice, first heated for $5 \mathrm{~h}$ at the ratio of $1: 10\left(\mathrm{~g} \cdot \mathrm{m}^{-1} \mathrm{~L}^{-1}\right)$, then heated for $3 \mathrm{~h}$ at the ratio of $1: 5\left(\mathrm{~g} \cdot \mathrm{m}^{-1} \mathrm{~L}^{-1}\right)$. The products of the two extractions were mixed and filtered to obtain a liquid extract. The solvents were retrieved by reduced pressure distillation, and the C. camphora extracts were dissolved in the respective solvents at desired concentrations and stored at $4^{\circ} \mathrm{C}$ for uses. 


\section{Sample preparation}

Brown-rot fungus (G. trabeum) was provided by the College of Life Science of Fujian Agriculture and Forestry University; White-rot fungus (C. versicolor) was provided by China Forestry Culture Collection Center. PS (potato and sucrose) medium: potato, 200 g; sucrose, $20 \mathrm{~g}$; and distilled water, $1,000 \mathrm{~mL}$.

\section{Experiment reagents}

Coomassie brilliant blue (CBB) G-250 staining, bovine serum albumin (FBS) medium, DNS medium, 3,5-dinitrosalicylic acid medium, acetic acid (HAc), sodium acetate, HAc-sodium acetate buffer solution, glucose standard solution, and 1\% hydroxymethyl cellulose (CMC) solution. These solutions and reagents were all produced by China National Pharmaceutical Group (Sinopharm).

\section{Main instruments and devices}

Laminar flow cabinet: HT-840.U, Suzhou Antai Airtech Co., Ltd. (Suzhou, China). Incubator: HHS.250B, Nanjing Hengyu Instrument Equipment Manufacture Co., Ltd. (Nanjing, China). Magnetic stirrer: 79HW-1, Jintan Ronghua Instrument Manufacture Co., Ltd. (Nanjing, China). Bacteria shaker: ZHWY-211B, Shanghai Zhicheng Instrument Manufacture Co., Ltd. (Shanghai, China). Micro-barometer: DMPY-2C, institute of applied physics of Nanjing University (Nanjing, China). UV spectrophotometer: UV-1100, Shanghai Mapade Instruments Co., Ltd. (Shanghai, China). Conductometer: 3173-COND, Shanghai Jenco Co., Ltd. (Shanghai, China). Oxygen consumption measurement instrument (homemade: magnetic stirrer, DP-AW micro-barometer, and water bath).

\section{Wood-decay fungus aerobic respiration measurement}

$\mathrm{NaOH}$ can absorb the $\mathrm{CO}_{2}$ generated by wood-decay fungus during respiration. In a closed environment and under constant volume and temperature, changes in pressure are indicative of $\mathrm{CO}_{2}$ generation or consumption, and thus alterations in pressure can be used to calculate the respiration rate of wood-decay fungus. The instrument used for measuring oxygen consumption is shown in Fig. 1.

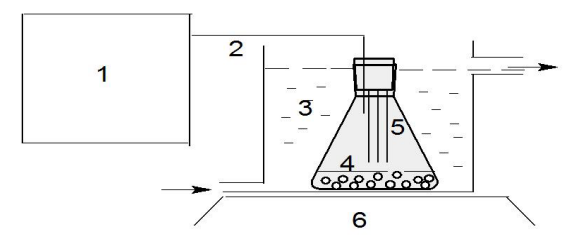

Fig. 1: Device of respiration determination: 1. Micro-pressure difference, 2. Gas catheter, 3. Constant temperature bath, 4. Mycelium suspension, 5. Gauze (soaked with 10\% NaOH), 6. Magnetic stirrer.

A sterile culture medium was prepared in a $100-\mathrm{mL}$ Erlenmeyer flask and five different concentrations were included: $0.2 \mathrm{~g} \cdot \mathrm{L}^{-1}, 0.4 \mathrm{~g} \cdot \mathrm{L}^{-1}, 0.6 \mathrm{~g} \cdot \mathrm{L}^{-1}, 0.8 \mathrm{~g} \cdot \mathrm{L}^{-1}$, and $1 \mathrm{~g} \cdot \mathrm{L}^{-1}$. In each culture flask, five pieces of a $7 \mathrm{~mm}$ fungus cake were inoculated. A piece of gauze soaked with $10 \%$ $\mathrm{NaOH}$ was placed at the opening part of the flask to absorb CO2. The flasks were incubated at $28^{\circ} \mathrm{C}$ in a water bath and placed on a magnetic stirrer (stirring for $15 \mathrm{~min}$ ). Then, the flasks were connected to a microbarometer. Once the reaction was stable, the measuring instrument was reset to zero. The pressure inside of the flask was recorded every $10 \mathrm{~min}$ for a total of $160 \mathrm{~min}$. During 
the measurement, the same flask and microbarometer were used to calculate the respiration rate under different medium concentrations.

\section{Cellulase activity measurement}

Under alkaline conditions, 3,5-dinitrosalicylic acid (DNS) reacts with reducing sugars to form 3-amino-5-nitrosalicylic acid. 3-amino-5-nitrosalicylic acid presents a red-brown color under boiling conditions, and the color is proportional to the amount of reducing sugars. Therefore, a colormetric method can be used to measure reducing sugar content. Moreover, DNS reacts with a broad range of reducing sugars, not only with specific groups. Thus, DNS is suitable for measuring the amount of sugar that is reduced from a polysaccharide (cellulose, hemicellulose, and starch) hydrolysis reaction (Dashtban et al. 2010).

G. trabeum hyphae were incubated in the stove until the fast growing stage (about 15 days, wherein cellulose secretion is at the highest level). The collected hyphae were vacuum filtrated and the obtained filtrate was used for enzyme activity measurement.

\section{G. trabeum leakage protein content measurement}

Coomassie brilliant blue (CBB) was used to measure G. trabeum leakage protein content after treatment with the C. camphora xylem extracts. CBB G-250 is red when in an unbound state and has a maximal absorption value at a wavelength of $488 \mathrm{~nm}$, its bonds with proteins and forms a complex. The complex presents bright blue color and has a maximal absorption value at a wavelength of $595 \mathrm{~nm}$. Moreover, the absorption value is proportional to the amount of proteins, thus CBB G-250 can be used for protein content measurement. G. trabeum was treated with ethyl acetate extracts of $C$. camphora xylem for $24 \mathrm{~h}$. Different concentrations of ethyl acetate extracts were included: $0.2 \mathrm{~g} \cdot \mathrm{L}^{-1}, 0.4 \mathrm{~g} \cdot \mathrm{L}^{-1}, 0.6 \mathrm{~g} \cdot \mathrm{L}^{-1}, 0.8 \mathrm{~g} \cdot \mathrm{L}^{-1}$, and $1 \mathrm{~g} \cdot \mathrm{L}^{-1}$. After ethyl acetate extracts of C. camphora xylem treatment, G. trabeum solutions were filtered, and the filtrates were kept. A 1-mL aliquot of the filtrate was mixed with $5 \mathrm{~mL}$ of the $\mathrm{CBB}$ solution, and the mixture was incubated for $10 \mathrm{~min}$. Its absorption was measured at a wavelength of $595 \mathrm{~nm}$, and each treatment was repeated thrice. Protein content was calculated using the standard curve generated using albumin from bovine serum (BSA).

To generate the standard curve, albumin from bovine serum was dissolved in Milli-Q at a concentration of $100 \mathrm{mg} \cdot \mathrm{L}^{-1}$. BSA was added to seven glass tubes (numbered from $0-6$ ) and diluted to the final concentration as described in Tab. 1.

Tab. 1: The preparation table of bovine serum albumin for test.

\begin{tabular}{|l|c|c|c|c|c|c|c|}
\hline Tube number & 0 & 1 & 2 & 3 & 4 & 5 & 6 \\
\hline $100 \mathrm{mg} \cdot \mathrm{L}^{-1}$ BSA solution $(\mathrm{mL})$ & 0.0 & 0.1 & 0.2 & 0.3 & 0.4 & 0.5 & 0.6 \\
\hline Coomassie brilliant blue solution $(\mathrm{mL})$ & 5 & 5 & 5 & 5 & 5 & 5 & 5 \\
\hline
\end{tabular}

Tube 0 was used as the blank control. The mixture was incubated for $10 \mathrm{~min}$ and its absorption was measured at a wavelength of $595 \mathrm{~nm}$. The standard curve was generated by plotting the protein concentration as the $\mathrm{X}$ axis and absorption as the $\mathrm{Y}$ axis. Based on the standard curve, a regression equation was calculated.

After adding BSA to each tube, the reaction was incubated for $10 \mathrm{~min}$, and absorption was measured. All obtained values subscribed the absorption value from tube 0 . A standard curve was generated by plotting the protein concentration as the $\mathrm{X}$ axis and the subscribed absorption value as the $\mathrm{Y}$ axis. Based on the standard curve, a regression equation was calculated. 


\section{G. trabeum conductivity measurement}

Cell membrane permeability of $C$. camphora xylem extract-treated wood-decay fungi was quantified by measuring the conductivity of the released electrolytes from cells and into the solutions. The higher the conductivity of the hyphae after treatment, the higher the cell membrane permeability. It is indicated that more electrolytes were released by the cells and into the solution (Tsujimoto et al. 2006). $M_{1}$ is the conductivity of hyphae after treatment. $M_{2}$ is the conductivity of the untreated hyphae.

G. trabeum was inoculated in a PS medium and incubated at $28^{\circ} \mathrm{C}$ for 6 days. The hyphae were vacuum-dried and washed with sterile water for several times. Then, $1 \mathrm{~g}$ of the hyphae was added to $30 \mathrm{~mL}$ of different concentrations of ethyl acetate extracts $\left(1 \mathrm{~g} \cdot \mathrm{L}^{-1}, 2 \mathrm{~g} \cdot \mathrm{L}^{-1}, 3 \mathrm{~g} \cdot \mathrm{L}^{-1}\right.$, $4 \mathrm{~g} \cdot \mathrm{L}^{-1}$, and $\left.5 \mathrm{~g} \cdot \mathrm{L}^{-1}\right)$. The hyphae conductivity of different samples was measured over time, and the sterile Milli-Q water group was used as the control group. The corrected conductivity was calculated using the following Eq. 1:

$$
\text { Corrected conductivity }=\mathrm{M}_{1}-\mathrm{M}_{2}
$$

\section{RESULTS AND DISCUSSION}

\section{The effect of $C$. camphora xylem extracts on $G$. trabeum and $C$. versicolor aerobic respiration}

Respiration is a central step for energy conversion and provides energy for various biological activities (Pedersen et al. 2012). In this study, the effect of $C$. camphora xylem extracts on G. trabeum and C. versicolor aerobic respiration was investigated. C. camphora extract-treated wood-decay fungi were kept in a sealed instrument that was kept under constant volume and temperature. $\mathrm{CO}_{2}$ generated from aerobic respiration was absorbed by $\mathrm{NaOH}$ and the resulting changes in pressure were recorded. Therefore, aerobic respiration rate was calculated. The results provide additional insights on fungal hyphae physiological conditions when the cellular membrane structure and function are altered.
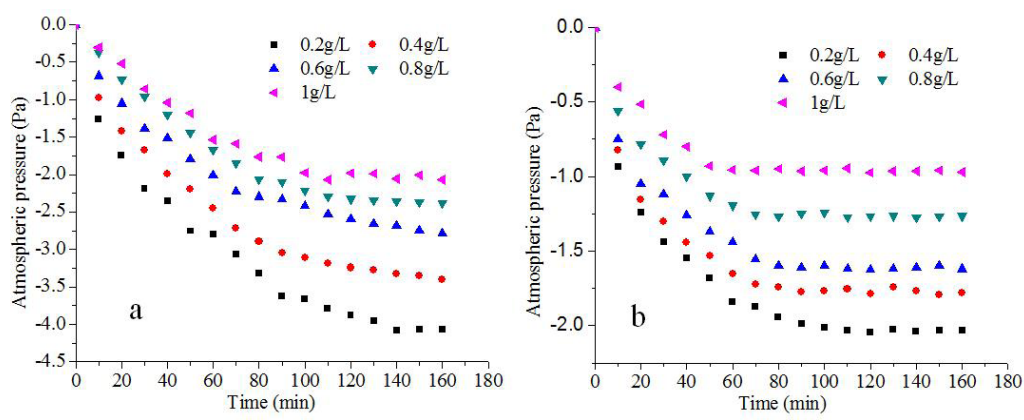

Fig. 2: Effect of G. trabeum on oxygen consumption of extracts of C. camphora: a) chloroform extracts of C. camphora, b) methanol extracts of C. camphora.

The methanol and chloroform extracts of C. camphora xylem inhibited G. trabeumi aerobic respiration (Fig. 2). With increased extract concentration, alterations in pressure decreased and reached a plateau, indicating a decrease in the aerobic respiration rate of $G$. trabeumi. Therefore, 
the higher the concentration of extracts, the stronger the inhibitory effects. At the highest extract concentration ( $\left.1 \mathrm{~g} \cdot \mathrm{L}^{-1}\right)$, the respiration of chloroform extract-treated G. trabeumi was arrested 100 min after treatment; however, the respiration of methanol extract-treated G. trabeumi was arrested $50 \mathrm{~min}$ after treatment. The methanol extracts of $C$. camphora xylem showed better inhibitory effects on $G$. trabeumi respiration than the chloroform extracts of $C$. camphora xylem (when the same concentration was applied) because methanol extract-treated G. trabeumi showed a lower level of respiratory and pressure changes.
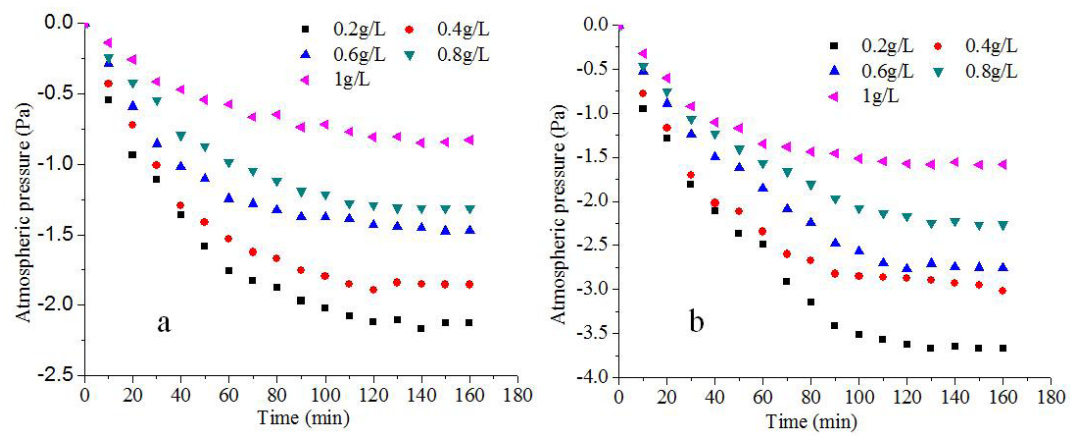

Fig. 3: Effect of C. versicolor on oxygen consumption of extracts of C. camphora: a) chloroform extracts of C. camphora, b) methanol extracts of C. camphora.

The methanol and chloroform extracts of C. camphora xylem also inhibited C. versicolor aerobic respiration (Fig. 3). When C. versicolor was treated with $0.2 \mathrm{~g} \cdot \mathrm{L}^{-1}$ of chloroform extracts of C. camphora xylem, the difference in pressure increased and reached a plateau $110 \mathrm{~min}$ after treatment. When the concentration was increased to $1 \mathrm{~g} \cdot \mathrm{L}^{-1}$, the chloroform extracts of C. camphora xylem showed stronger inhibitory effects, and the difference in pressure was smaller and reached a plateau at $90 \mathrm{~min}$ after treatment. With increased concentration of the respective extract, pressure decreased at each time point and respiration was arrested at earlier time points. When the same concentration and treatment time were applied, the chloroform extracts of C. camphora xylem showed better inhibitory effects on $C$. versicolor respiration than the methanol extracts of C. camphora xylem because chloroform extract-treated C. versicolor showed a lower degree of change in pressure (Liu et al. 2003).

The results showed that the respiration of G. trabeumi and C. versicolor were significantly inhibited under all concentrations. With increased extract concentrations, the pressure decreased and respiration was completely arrested above certain concentrations. The results also showed that $G$. trabeumi was most sensitive to methanol extracts of $C$. camphora xylem; however, $C$. versicolor was most sensitive to chloroform extracts of $C$. camphora xylem. Both extracts significantly inhibited wood-decay fungal respiration.

\section{The effect of ethyl acetate extracts of $C$. camphora xylem on $G$. trabeum cellulase activity}

Different volumes $(0 \mathrm{~mL}, 0.2 \mathrm{~mL}, 0.4 \mathrm{~mL}, 0.6 \mathrm{~mL}, 0.8 \mathrm{~mL}$, and $1.0 \mathrm{~mL})$ of standard glucose solution $\left(1 \mathrm{mg} \cdot \mathrm{m}^{-1} \mathrm{~L}^{-1}\right)$ were added to a $25 \mathrm{~mL}$ tube and distilled water was added to a final volume of $1.0 \mathrm{~mL}$. In each tube, $1.5 \mathrm{~mL}$ of the DNS reagent was added. The tubes were first incubated for $5 \mathrm{~min}$ in a water bath and then cooled in running water. Distilled water was added to a 
final volume of $20 \mathrm{~mL}$. The absorption of each tube was measured at a wavelength of $540 \mathrm{~nm}$. A standard curve was generated and is shown in Fig. 4.

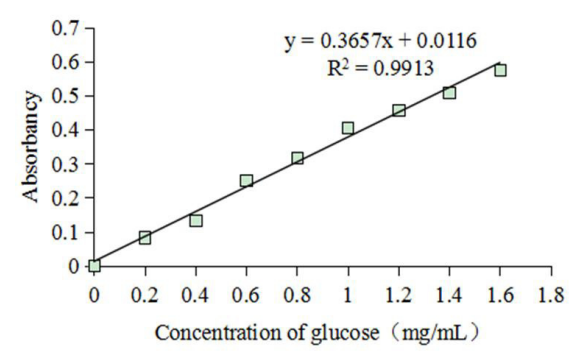

Fig. 4: Standard curve of glucose.

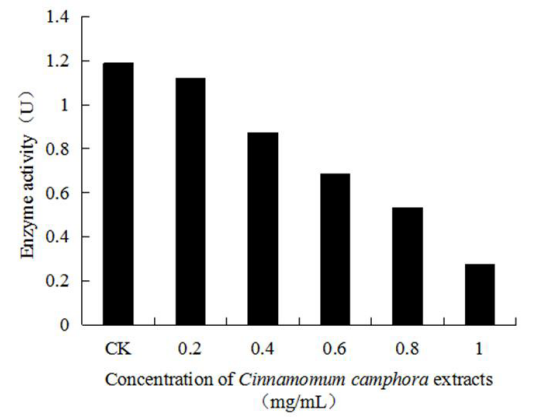

Fig. 5: The effect of extracts on the enzyme activity of cellulase of G. trabeum.

With increased concentration of ethyl acetate extracts of $C$. camphora xylem, cellulase activity of G. trabeumi decreased (Fig. 5). Starting from $0.2 \mathrm{mg} \cdot \mathrm{m}^{-1} \mathrm{~L}^{-1}$, ethyl acetate extracts of $C$. camphora xylem showed significant inhibition of G. trabeumi cellulase activity. When the concentration reached $1 \mathrm{mg} \cdot \mathrm{m}^{-1} \mathrm{~L}^{-1}$, the extracts showed strongest inhibition, showing $>50 \%$ inhibition of enzyme activity. These findings indicate that ethyl acetate extracts of $C$. camphora xylem can significantly inhibit G. trabeumi cellulase activity, which is the main functional enzyme for G. trabeumi to decay woods (Yu et al. 2018).

\section{The effect of ethyl acetate extracts of $C$. camphora xylem on G. trabeum conductivity}

Changes in the conductivity of C. camphora ethyl acetate extract-treated G. trabeum hyphae are shown in Fig. 6.

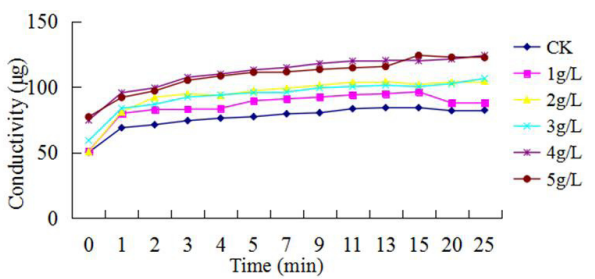

Fig.6: The effect of extracts on the cells conductivity of G. trabeum.

Compared to the control group (CK), all five concentrations of the ethyl acetate extracts of C. camphora xylem induced an increase in G. trabeum hyphae conductivity. The higher the concentration of ethyl acetate extracts of $C$. camphora xylem, the higher the G. trabeum hyphae conductivity. When treated with $4 \mathrm{~g} \cdot \mathrm{L}^{-1}$ or $5 \mathrm{~g} \cdot \mathrm{L}^{-1}$ of ethyl acetate extract of C. camphora xylem, the conductivity significantly increased. After ethyl acetate extract treatment, the intracellular contents $G$. trabeum hyphae were released, thereby resulting in an increase in conductivity; between $1 \mathrm{~min}$ and $7 \mathrm{~min}$ after treatment, the conductivity rapidly increased and reached the highest level at 11 min after treatment. However, in the control group, the conductivity slowly increased and reached the highest level at $15 \mathrm{~min}$ after treatment. Using same amount of hyphae, changes in conductivity reflect the total amount of intracellular electrolytes, thus indicating changes in cell membrane permeability (Xiushu et al. 2018). 


\section{The effect of ethyl acetate extracts of C. camphora xylem on G. trabeum leakage protein content}

After treatment with different concentrations of ethyl acetate extracts of $C$. camphora xylem for $24 \mathrm{~h}$, the amount of leakage protein from G. trabeum hyphae was measured (Fig. 7).

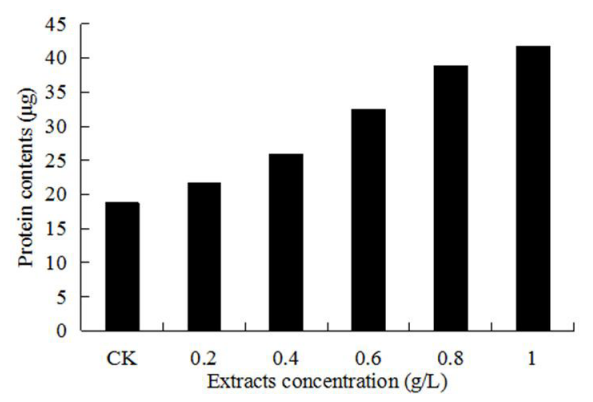

Fig. 7: The effect of extracts on the leakage of protein from the cells of G. trabeum.

With increased concentration of ethyl acetate extracts of C. camphora xylem, the amount of leaked protein also increased. When the concentration reached $1 \mathrm{~g} \cdot \mathrm{L}^{-1}$, the highest amount of leaked protein was observed. Leakage protein content further indicated that ethyl acetate extracts of C. camphora xylem can change G. trabeum cell membrane permeability, thus releasing more proteins (Tsujimoto and Shimizu 2007). The results obtained in this experiment, combined with conductivity experiment, demonstrate that ethyl acetate extracts of C. camphora xylem can increase G. trabeum cell membrane permeability.

\section{CONCLUSIONS}

A large number of chemical compounds in the $C$. camphora xylem extracts has a variety of biological activity and certain application value. Methanol extracts of $C$. camphora xylem showed stronger inhibitory effects on G. trabeum aerobic respiration and chloroform extracts of $C$. camphora xylem showed stronger inhibitory effects on $C$. versicolor aerobic respiration. Ethyl acetate extracts of C. camphora xylem exhibited good inhibitory effect on to G. trabeum cellulase activity. The experimental results of conductivity show that the ethyl acetate extract of C. camphora xylem could increase G. trabeum cellular membrane permeability. The leakage of protein from the cells of G. trabeum reflects that ethyl acetate extracts of C. camphora xylem can change G. trabeum cell membrane permeability.

\section{ACKNOWLEDGMENTS}

This research was supported by the National Natural Science Foundation of China (No. 31760191), Undergraduate Teaching Content and Curriculum System Reform Foundation of Guizhou Province (No.2018520134) and Graduate Student Research Foundation of Guizhou Province (YJSCXJH (2019) 104). 


\section{REFERENCES}

1. Bhardwaj, S.K., Singla, S.K., Bhardwaj, R.K., 2012: Evaluation of plant extracts as antifungal agents against wood rotting fungi Coriolus versicolor (L.: Fr.) Quelet. Journal of the Indian Academy of Wood Science 9: 62-65.

2. Dashtban, M., Maki, M., Leung, K.T., Mao, C., Qin, W., 2010: Cellulase activities in biomass conversion: Measurement methods and comparison. Critical Reviews in Biotechnology 30(4): 302-315.

3. Suhua, Y., Shunzhong, L.U., Mi, Q. Yufen, L., 2018: Analysis on components of high content o-cymene from Cinnamomum camphora essential oil. Journal of Forestry Engineering 3(1): 49-53.

4. Guo, S., Geng, Z., Zhang, W., Liang, J., Wang, C., Deng, Z., Du, S., 2016: The Chemical composition of essential oils from Cinnamomum camphora and their insecticidal activity against the stored product pests. International Journal of Molecular Sciences 17(11): 1836-1849.

5. Yu, J., Xu, J., Fan, Y., 2018: A review of antibacterial properties of chitosan. Journal of Forestry Engineering 3(5): 20-27.

6. Janin, A., Coudert, L., Riche, P., Mercier, G., Cooper, P., Blais, J.F., 2011: Application of a CCA-treated wood waste decontamination process to other copper-based preservativetreated wood after disposal. Journal of Hazardous Materials 186(2-3): 1880-1887.

7. Kahl, T., Arnstadt, T., Baber, K., Bässler, C., Bauhus, J., Borken, W., Buscot, F., Floren, A., Heibl, C., Hessenmöller, D., 2017: Wood decay rates of 13 temperate tree species in relation to wood properties, enzyme activities and organismic diversities. Forest Ecology and Management 391: 86-95.

8. Kerem, Z., Jensen, K.A., Hammel, K.E., 1999: Biodegradative mechanism of the brown rot basidiomycete Gloeophyllum trabeum: evidence for an extracellular hydroquinone-driven fenton reaction. FEBS Letters 446: 49-54.

9. Mehmet Budakci, Cihat Taşcioğlu., 2009: Adhesion properties of woods treated with copper based wood preservative chemicals. Wood Research 54(3): 23-32.

10. Kumari, S., Jain, P., Sharma, B., Kadyan, P., Dabur, R., 2015: In vitro antifungal activity and probable fungicidal mechanism of aqueous extract of Barleria Grandiflora. Applied Biochemistry and Biotechnology 175: 3571-3584.

11. Lee, H.J., Hyun, E.A., Yoon, W.J., Kim, B.H., Man, H.R., Kang, H.K., Cho, J.Y., Yoo, E.S., 2006: In vitro anti-inflammatory and anti-oxidative effects of Cinnamomum camphora extracts. Journal of Ethnopharmacology 103(2): 208-210.

12. Leskinen, T., Salas, C., Kelley, S.S., Argyropoulos, D.S., 2015: Wood extractives promote cellulase activity on cellulosic substrates. Biomacromolecules 16(10): 3226-3238.

13. Li, Q., Li, Q. Lin, J., Li, J., Wu, H., Liu, J., Wang, X., 2016: Decay resistance effects of Pinus massoniana treated with different preservatives based on pyrolysis and thermodynamics. Wood Science and Technology 50: 105-116.

14. Li, Q., Wang, X.X., Lin, J.G., Liu, J., Jiang, M.S., Chu, L.X., 2014: Chemical composition and antifungal activity of extracts from the Xylem of Cinnamomum camphora. BioResources 9(2): 383-399.

15. Li, Q., Xu, L., Wu, H., Liu J., Lin J. G., Guan X., 2018: Differential proteome analysis of the extracts from the xylem of Cinnamomum camphora inhibiting Coriolus versicolor. Holzforschung 72(6): 459-466. 
16. Liu, Y., Laks, P., Heiden, P., 2003: Nanoparticles for the controlled release of fungicides in wood: soil jar studies using G. trabeum and T. Versicolor wood decay fungi. Holzforschung 57(2): 135-139.

17. Matsubara, M., Kuroda, H., 2008: Physiological and biochemical studies on germinating fungal spores IV. Accumulation of glutamine and its origin in germinating conidia of Cochliobolus miyabeanus. Chemical \& Pharmaceutical Bulletin 28(5): 1365-1373.

18. Miyazawa, M., Hashimoto, Y., Taniguchi, Y., Kubota, K., 2001: Headspace constituents of the tree remain of Cinnamomum camphora. Natural Product Letters 15(1): 63-69.

19. Palanti, S., Feci, E., Predieri, G., Vignali, F., 2009: Copper anchored to amino-group functionalized silica gel as wood preservative against brown-rot decay. Maderas Ciencia Y Tecnología 12(3): 259-266.

20. Pedersen, M.B., Gaudu, P., Lechardeur, D., Petit, M.A., Gruss, A., 2012: Aerobic respiration metabolism in lactic acid bacteria and uses in biotechnology. Annual Review of Food Science and Technology 3: 37-58.

21. Xiushu, Y., Huaping, W.U., Prosper, N.K., Jin, R., Yan, Z., Fangli, S., 2018: Preparation of crosslinked chitosan/poly (vinyl alcohol) and its construction in bamboo. Journal of Forestry Engineering 3(3): 57-62.

22. Roszaini, K., Nor Azah, M.A., Mailina, J., Zaini, S., Mohammad, F.Z., 2013: Toxicity and antitermite activity of the essential oils from Cinnamomum camphora, Cymbopogon nardus, Melaleuca cajuputi and Dipterocarpus sp. against Coptotermes curvignathus. Wood Science and Technology 47: 1273-1284.

23. Schubert, M., Fink, S., Schwarze, F., 2008: Evaluation of Trichoderma spp. as a biocontrol agent against wood decay fungi in urban trees. Biological Control 45 (1): 111-123.

24. Schultz, T.P., Nicholas, D.D., Preston, A.F., 2007: A brief review of the past, present and future of wood preservation. Pest Management Science 63: 784:795.

25. Liu Z. Z., Deng, B. Q. Li S. L., Zou Z. R., 2018: Optimization of solvent-free microwave assisted extraction of essential oil from Cinnamomum camphora leaves. Industrial Crops and Products 124: 353-362.

26. Susi, P., Aktuganov, G., Himanen, J., Korpela, T., 2011: Biological control of wood decay against fungal infection. Journal of Environmental Management 92(7): 1681-1689.

27. Syehee, A., Seichang, O., Ingyu, C., Han, G.S., Hanseob, J., Kiwoo, K., Youngho, Y., Yang, I., 2010: Environmentally friendly wood preservatives formulated with enzymatichydrolyzed okara, copper and/or boron salts. Journal of Hazardous Materials 178(1-3): 604-615.

28. Tsujimoto, Y., Nakagawa, T., Shimizu, S., 2006: Mitochondrial membrane permeability transition and cell death. Biochimica et Biophysica Acta (BBA) - Bioenergetics 1757(9-10): 1297-1300.

29. Tsujimoto, Y., Shimizu, S., 2007: Role of the mitochondrial membrane permeability transition in cell death. Apoptosis 12: 835.

30. Voda, K., Boh, B., Vrtačnik, M., Pohleven, F., 2003: Effect of the antifungal activity of oxygenated aromatic essential oil compounds on the white-rot Trametes versicolor and the brown-rot Coniophora puteana. International Biodeterioration \& Biodegradation 51(1): 51-59.

31. Zhang, J., Presley, G.N., Hammel, K.E., Ryu, J.S., Menke, J.R., Figueroa, M., Hu, D., Orr, G., Schilling, J.S., 2016. Localizing gene regulation reveals a staggered wood decay mechanism for the brown rot fungus Postia placenta. Proceedings of the National Academy of Sciences of the United States of America 113(39): 10968-10979. 
Huimin Zhang, Kai Tu, Qiandong Hou

Guizhou University

Key Laboratory of Plant Resource Conservation And Germplasm Innovation in Mountainous Region (Ministry of Education) Institute of Agro-Bioengineering/ College of Life Science

Institute For Forest Resources \& Environment of Guizhou/ College of Forestry

GuiYang 550025

P. R. China

Hui LiN*

Ningde Normal University

Fujian Provincial Key Laboratory of Featured Materials In Biochemical Industry Fujian Province University Key Laboratory of Green Energy and Environment Catalysis, College of Chemistry And Materials

Ningde

P. R. China

*Corresponding author: linhui@ndnu.edu.cn

QUan Li*

Kaili University

KaILI 5560II

P. R. China

*Corresponding author: liquan-8@163.com 
